\title{
Resenha / Critial Review
}

por Marcos César Alves Siqueira ${ }^{1}$

\section{Maria da Glória Gohn}

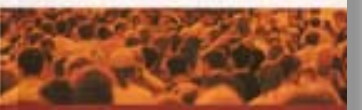

MOVIMENTOS SOCIAIS

E REDES DE MOBILZACOESS CWVIS

WO BRASIL CONIEMTORLLEO

GOHN, Maria da Glória. Movimentos Sociais e Redes de Mobilizações Civis no Brasil Contemporâneo. Petrópolis, RJ: Vozes, 2010.

Em Movimentos Sociais e Redes de Mobilizações Civis no Brasil Contemporâneo, Maria da Glória Gohn, professora da Faculdade de Educação da Unicamp e referência no estudo dos movimentos sociais, realiza, como ela mesma afirma, um mapeamento das principais ações coletivas, organizadas em movimentos, redes de mobilização ou associações civis da atualidade. Os dados e o formato inicial do livro originam-se da pesquisa O protagonismo da Sociedade Civil, que teve apoio do CNPq, e do Mapa da rede de instituições e ativos institucionais - as redes de movimentos sociais, ONGs, fóruns e conselhos. Trata-se, portanto, a obra, de uma síntese de 40 anos de experiência em estudos, pesquisas e reflexões sobre movimentos sociais.

O foco do mapeamento são as áreas temáticas e seus eixos de manifestações como problemas sociais e a contextualização desses problemas, sua localização geográfica, seus objetivos programáticos e características das suas redes de mobilização.

\footnotetext{
Mestrando do Programa de Pós-Graduação em Política Social, do Departamento de Serviço Social da Universidade de Brasília - UnB, e Pesquisador do Núcleo de Estudos e Pesquisas em Política Social, do Centro de Estudos Avançados Multidisciplinares da Universidade de Brasília (NEPPOS/CEAM/UnB).E-mail: mcasiqueira@gmail.com
} 
Além disso, são discutidas as categorias analíticas mais debatidas na atualidade - rede e mobilização social - com seus vários paradigmas teóricos, sem, contudo, considerá-las substitutas da categoria movimentos sociais.

Com efeito, o livro em apreço, o $15^{\circ}$ de autoria individual de Glória Gohn, não se prende a meras listagens, mas apresenta um painel temático e histórico das organizações sociais estudadas, conforme suas próprias palavras:

imaginem telas de um filme sendo abertas, sequencialmente, descortinando cenários de sujeitos em movimento (...) A meta perseguida neste desfilar de cenas, cenários e paisagens é a de que se possa fazer um balanço das ações coletivas expressas em movimentos sociais que tanto podem ter caráter emancipatório e transformador, como meramente integratório e conservador (p. 08).

Neste sentido, a autora descreve os problemas detectados de acordo com as suas linhas temáticas, assim como os Movimentos e Organizações correspondentes, retratando de forma crítica as suas dinâmicas, de modo que o retrato seja o mais fiel possível. Ou melhor, de sorte a garantir que a fotografia produzida não seja apagada, borrada ou inerte, mas que não seja também colorida demais, louvatória, com tons propagandísticos (p. 08).

Como objetivo final, o livro pretende fomentar o debate sobre os movimentos organizados, voltados para a transformação da realidade social, destacando a dicotomia existente entre os movimentos de emancipação e os de controle social. Contém duas partes ou divisões, sendo que, na primeira, é realizada uma análise da conjuntura na qual os movimentos estão inseridos, com destaque para as categorias analíticas referentes a essas organizações. E, na segunda, são descritas as diversas formas de associativismo, organizadas em 10 eixos temáticos: 1 - Movimentos ao redor da questão urbana; 2 - Movimentos em torno da questão 
do meio ambiente: urbano e rural; 3 - Movimentos identitários e culturais: gênero, etnia e gerações ; 4 - Movimentos de demandas na área dos direitos; 5 - Movimentos ao redor da questão da fome; 6 - Mobilizações e movimentos sociais: área do trabalho; 7 Movimentos decorrentes de questões religiosas; 8 - Mobilizações e movimentos sociais rurais; 9 - Movimentos sociais no setor das comunicações; e 10 - Movimentos sociais globais.

$\mathrm{Na}$ primeira parte são ainda destacados cinco pontos de diferenciação dos movimentos sociais atuais em relação aos do passado, quais sejam:

1 - Houve redefinição na sua própria identidade e na qualificação do tipo de suas ações. Esta mudança está menos focada em pressupostos ideológicos, como no passado, e mais nos vínculos de integração com esferas da sociedade, organizadas segundo critérios de cor, raça, gênero, habilidades e capacidades, bem como de conscientização e geração de saberes. Além disso, os movimentos sociais da atualidade, ao atuarem num cenário contraditório, em que políticas, programas e projetos podem engessá-los, discutem e problematizam a esfera pública com vista à construção de novos modelos organizativos;

2 - Os movimentos do passado possuíam papel essencialmente universalizante, uma vez que lutavam pelo "direito a ter direitos" (p. 17). Mas, hoje, o que se busca é o reconhecimento e o respeito às diferenças e às demandas e características particulares, representados pelos movimentos identitários. Atualmente existe grande variedade de organizações, articulações, projetos e experiências, refletindo a ampliação do leque dos movimentos sociais;

3 - O próprio Estado está reconfigurando as suas relações com a sociedade e gradualmente reconhecendo a 
existência desses novos sujeitos coletivos. No entanto, conforme Gohn aponta, disso decorre uma inversão de papéis: ao estabelecer relações com os movimentos sociais, o Estado passa a exercer uma influência política "de cima para baixo", retirando deles o seu caráter político e de pressão. Em outras palavras, os movimentos sociais passam a sofrer forte influência e até mesmo controle das estruturas políticas do Estado, que transformam as identidades políticas dos movimentos, e fazem com que a demanda coletiva seja suplantada por uma série de outras demandas específicas, isoladas e débeis. E, em decorrência, o Estado torna-se o único ponto de integração e convergência.

4 - Com a alteração do formato das mobilizações neste milênio e a ampliação dos sujeitos coletivos, os movimentos sociais estão agora dispostos em redes associativas, graças à profusão de novas tecnologias de comunicação. Isso decorre também do alargamento das fronteiras dos conflitos, como a questão migratória e imigratória e de acesso a recursos estratégicos, como água, energia, terra, etc. Esses conflitos, por sua vez, deixam de ter somente como eixo os Movimentos Sociais $x$ Estado, e referenciam-se em novos eixos, incluindo corporações e outros agentes econômicos interessados em tais recursos.

5 - Continuam prevalecendo grandes lacunas na produção teórica e acadêmica acerca dos movimentos sociais, apesar de sua recorrente presença na literatura das Ciências Sociais. Tais lacunas dizem respeito ao próprio conceito de movimento social e englobam: a sua qualificação como novos; a sua distinção de outras ações coletivas ou organizações sociais, como as ONGs; as conseqüências de sua institucionalização; e o seu 
papel no atual momento histórico. Estas lacunas têm dificultado o entendimento e o mapeamento corretos da categoria movimentos sociais, a qual se vê suplantada pela categoria mobilização social, que pode ser entendida como simples participação e cooperação muitas vezes induzidas por estruturas políticas externas a ela.

$\mathrm{Na}$ segunda parte do livro, a autora realizou um mapeamento dos principais atores sociais responsáveis pelas ações coletivas, agrupando-os em quatro eixos temáticos ou sujeitos: a) Os movimentos sociais (como categoria empírica ou conceitual); b) As ONGs, entidades assistenciais e entidades do chamado Terceiro Setor; c) Os fóruns; e d) Os conselhos gestores, programas ou políticas sociais. Desses atores, apenas os conselhos gestores não foram tratados, pois constituíram objeto de estudo específico no livro publicado em 2001, pela própria autora, e intitulado Conselhos gestores e participação sociopolítica. Nesta parte, Gohn indica as diferenças entre movimentos sociais e ações ou redes de mobilização civis, salientando que, enquanto os primeiros mobilizam idéias, consciências e demandas, as segundas podem ser organizadas de cima para baixo; ou seja, podem sofrer influência política direta, limitando-se a ações pontuais, de cunho conciliador e não transformador.

Mas a autora conclui apontando para a importância da inclusão da categoria mobilização social (dentro de um contexto de transformação política) nas pautas das principais discussões e estudos das Ciências Humanas e Sociais. Além disso, e seguindo a tônica de toda a obra, reforça a importância de nunca se dissociar o sujeito movimento social do seu contexto histórico, pois a identidade do primeiro surge e se molda no segundo. Para ela, os movimentos sociais são, acima de tudo, entidades capazes de aprender sobre o mundo e sobre si, alterando e revendo suas demandas, propostas e parcerias. 
Entretanto, em que pese a obra conter análises consistentes sobre o seu tema central, uma observação merece ser feita quando fala do novo cenário das políticas públicas no Brasil. A afirmação de que esse cenário criou um deslocamento da desigualdade econômica (com ênfase na renda) para a social (com ênfase nas características sociais e culturais) pode obscurecer o fato de que a distribuição de renda mínima continua sendo a "tábua da salvação" para o combate à pobreza no país; e que esse fato explica a implementação de políticas sociais focalizadas na extrema pobreza, em oposição às políticas sociais universais, verdadeiramente públicas. Todavia, é com lucidez que, nesse cenário, a autora se refere a dois outros deslocamentos a seu ver contraditórios: da questão da desigualdade (que não deve ser tolerada) para as diferenças, ou diversidades (que devem ser respeitadas), e da desigualdade para a equidade. O enfrentamento da complexidade desse cenário tem, segundo ela, propiciado, de um lado, a atualização das práticas e reivindicações das ações coletivas, mas, de outro lado, produzido retrocessos dessas ações para antigas formas clientelistas.

Finalmente, cabe registrar que este livro de Maria da Glória Gohn é de importância inconteste tanto para os que desejam ter uma visão ampla dos movimentos sociais do Brasil contemporâneo, de suas características e condicionantes, quanto uma compreensão fundamentada da identidade e da importância destes sujeitos na construção democrática. Por tratar de um campo teórico ainda carente de estudos e pesquisas, o referido livro terá papel fundamental no preenchimento de lacunas analíticas existentes e na catalisação de debates sobre o que se propôs tematizar. 